\title{
A PEDAGOGIA DA AUTONOMIA E A APRENDIZAGEM COLABORATIVA NOS CURSOS EAD
}

\section{LA PEDAGOGÍA DE LA AUTONOMÍA Y EL APRENDIZAJE COLABORATIVO EN LOS CURSOS EAD}

\section{THE PEDAGOGY OF AUTONOMY AND COLLABORATIVE LEARNING IN THE EAD COURSES}

\author{
Katiana NORMANDIA ${ }^{1}$ \\ Luana $\mathrm{CANTO}^{2}$
}

RESUMO: Este artigo visa analisar a relação entre a prática pedagógica de Paulo Freire e a Educação a Distância, que seja interativa e colaborativa. Dada a expansão acelerada de cursos EaD no Brasil nos últimos anos, principalmente em graduações e pósgraduações, faz-se necessário avaliar até que ponto as práticas educacionais de Paulo Freire podem contribuir para uma melhor aprendizagem com o uso da EaD como ferramenta democratizadora de acesso ao ensino.

PALAVRAS-CHAVE: Educação a distância. Aprendizagem colaborativa. Autonomia.

RESUMEN: Este artículo busca analizar la relación entre la práctica pedagógica de Paulo Freire y la Educación a Distancia, que sea interactiva y colaborativa. Dada la expansión acelerada de cursos EaD en Brasil en los últimos años, principalmente en graduaciones y postgrados, se hace necesario evaluar hasta qué punto las prácticas educativas de Paulo Freire pueden contribuir a un mejor aprendizaje con el uso de la EaD como herramienta democratizadora acceso a la enseñanza.

PALABRAS-CLAVE: Educación a distancia. Aprendizaje colaborativo. Autonomía.

ABSTRACT: This article aims to analyze the relationship between the pedagogical practice of Paulo Freire, which is interactive and collaborative. Given the rapid expansion of distance education courses in Brazil in recent years, especially in graduate and postgraduate courses, it is necessary to assess to what extent the educational practices of Paulo Freire can contribute to better learning with the use of distance education as a democratizing tool access to education.

KEYWORDS: Distance education. Collaborative learning. Autonomy.

${ }^{1}$ Universidade Santo Amaro (UNISA), Santo Amaro - SP - Brasil. Tutora dos cursos online do Sebrae. E-mail: katiana_normandia@yahoo.com.br

${ }^{2}$ Universidade Santo Amaro (UNISA), Santo Amaro - SP - Brasil. Professora nos cursos de Pedagogia presencial e à distância. E-mail: luagcanto@gmail.com 


\section{Aprendizagem Colaborativa: breves considerações}

A escola tradicional, sob métodos tradicionais de ensino, pressupõe uma forma rígida de ensino, onde o professor é uma pessoa que passa informação e o aluno é receptor dessas informações. No entanto, num processo de aprendizagem colaborativa, a troca de ideias e aprendizado ocorrem mutuamente entre professor e aluno, de forma a incentivar a participação de todos.

Em um contexto escolar, a aprendizagem colaborativa seria duas ou mais pessoas trabalhando em grupos com objetivos compartilhados, auxiliando-se mutuamente na construção de conhecimento. "Ao professor, não basta apenas colocar, de forma desordenada, os alunos em grupo, deve sim criar situações de aprendizagem em que possam ocorrer trocas significativas entre os alunos e entre estes e o professor" (IRALA e TORRES, 2007, p. 71).

Nesta perspectiva, o processo de educação colaborativa permite que tanto o aluno quanto o professor tenham a oportunidade de debater o assunto estudado, colocando em perspectiva conceitos, ideias e diversas teorias.

Nesses tempos de desenvolvimento e expansão da educação a distância, propiciada pelo avanço das tecnologias de comunicação, o aprendizado colaborativo torna-se mais importante, como forma de estimular no estudante o pensamento crítico e, também, o trabalho em equipe.

"Essas formas de ensinar e aprender, segundo seus defensores, torna os alunos mais responsáveis por sua aprendizagem, levando-os a assimilar conceitos e a construir conhecimentos de uma maneira mais autônoma”. (IRALA e TORRES, 2007, p. 65)

Portanto, o conhecimento é algo que é construído socialmente, através da interação entre pessoas, e não é algo solitário. Embora o ato de estudar seja essencialmente solitário, de uma pessoa com um livro, por exemplo, o conhecimento, o debate, a troca de ideias e o consequente enriquecimento do repertório intelectual só são possibilitados através da interação social.

Dessa forma, a aprendizagem colaborativa:

Opondo-se a essa abordagem tradicional de ensino, que ainda está fortemente arraigada no cotidiano das escolas, essas propostas reconhecem o conhecimento prévio de cada estudante, sua experiência e seu entendimento de mundo. $\mathrm{O}$ processo ensino-aprendizagem não está mais centrado na figura do professor e o aluno exerce nele papel fundamental. $\mathrm{O}$ professor atua na criação de contextos e ambientes 
adequados para que o aluno possa desenvolver suas habilidades sociais e cognitivas de modo criativo, na interação com outrem (IRALA e TORRES, 2007, p. 65).

Embora seja facilitada pelo avanço das tecnologias de comunicação, e seja hoje mais disseminada, a aprendizagem colaborativa não é um conceito novo. Desde meados do século XX que educadores têm usado a aprendizagem colaborativa, pois, segundo esses educadores, seus alunos estariam mais bem preparados para as atividades profissionais e do dia a dia se fossem educados pelo método cooperativo.

O professor George Jardine, da Universidade de Glasgow, entre os anos de 1774 e 1826, pretendendo preparar os discentes para a plena participação na sociedade britânica, empregou técnicas de composição de textos em colaboração e o ensino de técnicas de comunicação e de trabalho em grupo (GAILLET, 1994). Já na educação formal, no início do século XIX, destacam-se as experiências de aprendizagem colaborativa da Lancaster School e da Common School Movement. "Ainda do final do século XIX, ressalta-se a experiência do Coronel Francis Parker, que desenvolve atividades de aprendizagem em grupo em algumas escolas públicas dos Estados Unidos". (IRALA e TORRES, 2007 p. 67)

Segundo os referidos autores, "Na Inglaterra, no início do século $\mathrm{XX}$, educadores das escolas de artes e ofícios já aplicavam um método de aprendizagem que era mais cooperativo" (IRALA e TORRES, 2007, p. 67).

Desta forma, onde a educação cooperativa foi implementada como método que prepara os alunos para o mundo profissional, para o dia a dia, a troca de ideias e o adequado manuseio de informações podem ser considerados diferenciais.

Estimular, sobretudo a proatividade de quem aprende, é o que está por trás das experiências de colaboração nas salas de aula hoje. Na educação a distância, é fundamental manter o aluno motivado, e, para isso, é importante que o método de ensino utilizado leve em consideração o aprendizado em colaboração.

\section{A "Pedagogia da Autonomia" e a EaD}

Sabidamente a $\mathrm{EaD}$, com a expansão e barateamento das tecnologias de comunicação, se tornou ferramenta importante para a democratização do acesso ao conhecimento. Em qualquer ponto do Brasil, basta uma conexão com a internet para que 
uma pessoa possa concluir um curso a distância. No entanto, ainda prevalecem dúvidas acerca da qualidade do ensino, sendo ele a distância.

Partindo dos conceitos levantados, e das orientações do livro "Pedagogia da Autonomia", de Paulo Freire, vamos analisar se é possível seguir as orientações dessa obra num curso de graduação EaD. E qual deve ser a qualificação do tutor que vai fazer a intermediação entre o aluno e o conteúdo do curso.

Em seu famoso livro "A Pedagogia da Autonomia", Paulo Freire estabelece alguns princípios que precisam ser seguidos dentro de um processo de educar. Segundo o autor, ensinar exige, entre outras coisas, rigorosidade metódica; pesquisa; respeito aos saberes do educando; e criticidade.

Paulo Freire não acompanhou essa expansão das tecnologias de comunicações digitais, uma vez que faleceu em 1997. Embora os cursos de educação a distância já existam há muitos anos no Brasil e no mundo, o desenvolvimento dos Ambientes Virtuais de Aprendizagem (AVA) é fenômeno muito recente.

Hoje, tanto educandos quanto educadores podem utilizar plataformas de comunicação dentro dos AVAs, o que possibilita a troca rápida de conhecimento, conceitos, teorias, etc. Essas plataformas possibilitam, sobretudo, que o processo de aprender e ensinar sejam em colaboração, o que enriquece ainda mais a troca de conhecimentos.

Esse processo colaborativo, e "vivo", onde a troca de conhecimento se torna algo mais dinâmico, pode atender a um dos princípios de Paulo Freire: a educação precisa ter rigorosidade metódica:

E essas condições implicam ou exigem a presença de educadores e de educandos criadores, instigadores, inquietos, rigorosamente curiosos, humildes e persistentes. Faz parte das condições em que aprender criticamente é possível a pressuposição por parte dos educandos de que o educador já teve ou continua tendo experiência da produção de certos saberes e que estes não podem a eles, os educandos, ser simplesmente transferidos. Pelo contrário, nas condições de verdadeira aprendizagem os educandos vão se transformando em reais sujeitos da construção e da reconstrução do saber ensinado, ao lado do educador, igualmente sujeito do processo. Só assim podemos falar realmente de saber ensinado, em que o objeto ensinado é apreendido na sua razão de ser e, portanto, aprendido pelos educandos (Freire, 1996, p. 15).

E esse processo de aprender, que podemos classificar como vivo, uma vez que instiga educandos e educadores, é algo a ser possibilitado pela educação a distância dentro dos ambientes virtuais de aprendizagem. 


\section{Considerações finais}

O objetivo deste artigo foi apresentar uma breve análise sobre a Educação Colaborativa e ressaltar sua relevância para a difusão do conhecimento no século XXI. Além disso, explanamos sobre a "Pedagogia da Autonomia", conceito criado e difundido por Paulo Freire, em livro de mesmo nome.

A educação colaborativa leva em consideração a capacidade de educadores e educandos se comunicarem e, dessa forma, tornar o processo de aprendizagem um organismo vivo, em constante mutação. Dentro disso, a "Pedagogia da Autonomia" é conceito chave e importante na difusão do conhecimento.

Embora o EaD seja um método muito antigo de ensinar, foi a partir do desenvolvimento e expansão da internet e suas ferramentas de comunicação, com o surgimento dos Ambientes Virtuais de Aprendizagem (AVA), que a educação a distância teve seu crescimento acelerado. Embora Paulo Freire tenha falecido antes dessa expansão, seus conceitos são de extrema importância dentro do EaD.

Nos cursos $\mathrm{EaD}$, é fundamental que, dentro dos Ambiente Virtuais de Aprendizagem (AVA), haja interação e colaboração entre educandos e tutores/educadores. Só assim para que os alunos e seus tutores se sintam motivados, e para que a educação a distância possa ganhar em qualidade tanto quanto os cursos presenciais.

\section{REFERÊNCIAS}

IRALA, Esrom Adriano F. TORRES, Patrícia Lupion. Aprendizagem Colaborativa. In: Algumas vias para entreter o pensar e o agir. Curitiba - PR, SENAR-PR, 2007. p.6595.

FREIRE, Paulo. Pedagogia da autonomia. São Paulo, Paz e Terra, 1996.

RIBAS, Isabel Cristina. Paulo Freire e a EaD: uma relação próxima e possível. Curitiba - PR. 2010. Disponível em:

<http://www.abed.org.br/congresso2010/cd/3042010090204.pdf>. Acesso em 14 out. 2016. 


\section{Como citar este artigo}

NORMANDIA, Katiana.; CANTO, Luana. A pedagogia da autonomia e a aprendizagem colaborativa nos cursos $\mathrm{EaD}$. Revista on line de Política e Gestão Educacional, Araraquara, v. 21, n. esp. 1, p. 793-798, out./2017. Disponível em: <http://dx.doi.org/10.22633/rpge.v21.n.esp1.out.2017.10058>. E-ISSN:1519-9029.

Submetido em: 09/06/2017

Aprovado em: 20/08/2017 